(C) [2005] IEEE. Reprinted, with permission, from [David G Dorrell, I. Chindurza and C. Cossar, Effects of rotor eccentricity on torque in switched reluctance Machines, Magnetics, IEEE Transactions on Oct. 2005]. This material is posted here with permission of the IEEE. Such ermission of the IEEE does not in any way imply IEEE endorsement of any of the University of Technology, Sydney's products or services. Internal or personal use of this material is permitted. However, permission to reprint/republish this material for advertising or promotional purposes or for creating new collective works for resale or redistribution must be obtained from the IEEE by writing to pubspermissions@ieee.org. By choosing to view this document, you agree to all provisions of the copyright laws protecting it 


\title{
Effects of Rotor Eccentricity on Torque in Switched Reluctance Machines
}

\author{
David G Dorrell Member IEEE, I. Chindurza and C. Cossar
}

\begin{abstract}
This paper describes a study into the effects of rotor eccentricity on the torque in a 4 phase $8 / 6$ switched reluctance machine. Finite element solutions are run with different degrees of rotor eccentricity and the current/flux linkage loops obtained for each phase. The work done is then obtained for each phase and the change in torque studied. The simulation work is verified experimentally.
\end{abstract}

Index Terms-Switched reluctance motors, rotor eccentricity, torque

\section{INTRODUCTION}

$\mathrm{R}$ ECENT work into noise and vibration in a switched reluctance motor when the rotor is not centered in the stator bore (eccentricity) [1] utilized an 8/6 switched reluctance motor (Fig. 1). One of the measured effects that was not discussed there was the effect of the eccentricity on the torque. The authors can find little in the literature on this topic so it reported here as an example.

\section{EXPERIMENTAL MACHINE AND EXPERIMENTAL MEASUREMENT OF TORQUE WITH ROTOR ECCENTRICITY}

When the eccentricity was measured with a nominal $33 \%$ static eccentricity $(0.1 \mathrm{~mm}$ radial movement compared to an airgap of $0.3 \mathrm{~mm}$ ) it was found that there was an increase in torque over a range of firing angles. This is shown in Fig. 2 where there are fours different sets of firing angles. The convention here is that the angle is zero when the previous rotor pole is aligned with phase 1 on the horizontal axis. The fully unaligned position occurs at rotor angle $=30^{\circ}$. Fig 1 illustrated the rotor postions with respect to Phase 1 . Th0 is the switch-on angle and the switch-off angle is ThC. The first three results had early turn-on $\left(31,28\right.$ and $\left.32^{\circ}\right)$ and early turnoff $\left(42,44\right.$ and $\left.48^{\circ}\right)$, these correspond to dwell angles of $11^{\circ}$, and $16^{\circ}$ for the second and third characteristics. These are not affected by speed (the DC rail voltage is $80 \mathrm{~V}$ and current is being chopped to maintain about 7.5 A). These appear to show an increase in torque when the rotor is eccentric. At switching angles of $35^{\circ}$ and $55^{\circ}$ (dwell angle $20^{\circ}$ ) the torque falls away

The authors are with the Department of Electronics and Electrical Engineering, University of Glasgow, Glasgow, G12 8LT, UK, (corresponding author: phone +_44-141-3302768, fax +44-141-3303158, email d.dorrell@elec.gla.ac.uk). with speed because the turn-on angle is delayed which results in the current turn-on becoming slower with increasing speed. In this instance there appears to be no change in torque with eccentricity. A common strategy is to maintain the dwell angle at a constant value and vary the turn-on point however three dwell angles were selected to investigate the effect over a dwell angle range (from short to overlap) with the mid dwell angle being tested at two different turn-on angles. The experimental rig allowed the rotor to be moved by means of movable bearing housing at each end. Space constraints means that a full description is not possible; however the rotor radial position could be carefully set by means of a screw to set the degree of static eccentricity and the direction of eccentricity could be set by rotation of the complete bearing mounting. Checking of the radial rotor position was possible by measurement of individual coil inductances.

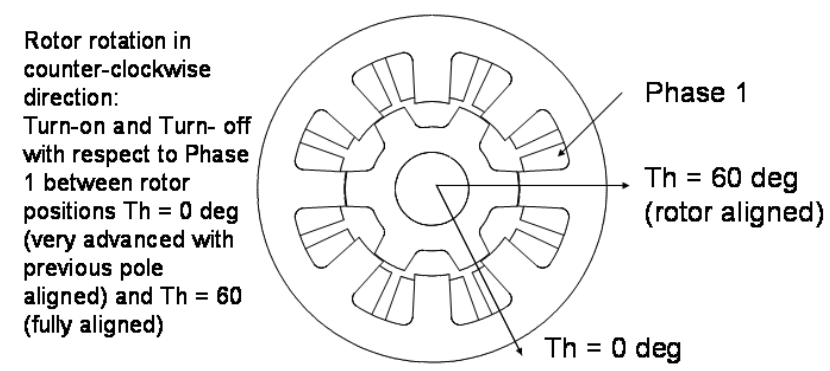

Fig. 1. Cross section of $8 / 6$ pole switched reluctance motor

\section{FINITE ELEMENT ANALYSIS - VARIATION OF TORQUE WITH ECCENTRICITY AND FIRING ANGLE}

A recent paper [2] looked at a similar problem using finite element analysis; although there were no experimental results, they came to a similar conclusion, i.e., rotor eccentricity increases the torque. However they assessed the performance in terms of airgap flux waves and used Maxwell stress tensors in the airgap to obtain instantaneous torque. Whilst this is a valid approach, it is unusual for a doubly-salient machine such as a switched reluctance machine; and a Maxwell stress in a finite element model has to be treated with care since it is liable to inaccuracies (although [2] appears to have obtained a good solution). The usual modeling technique is to use a current - flux linkage loop and calculate the area enclosed to obtain the work done during the switching action [3]. 


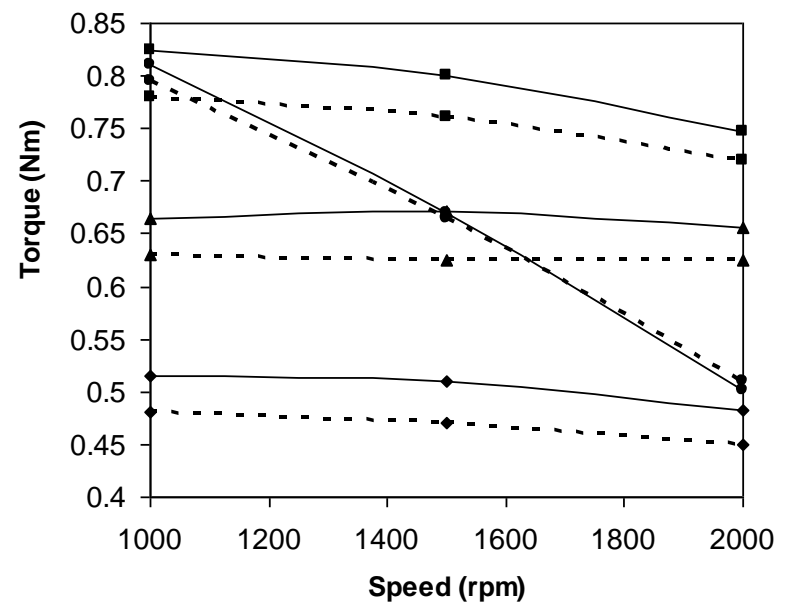

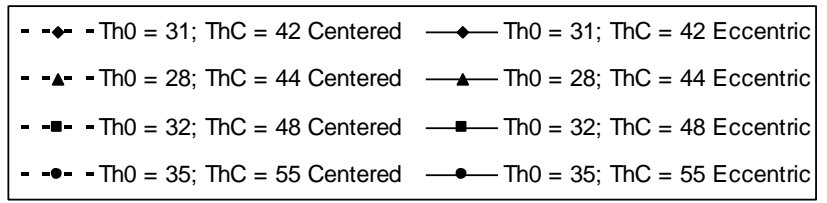

Fig. 2. Experimental torque measurements when rotor is centered and also has nominal $33 \%$ static eccentricity

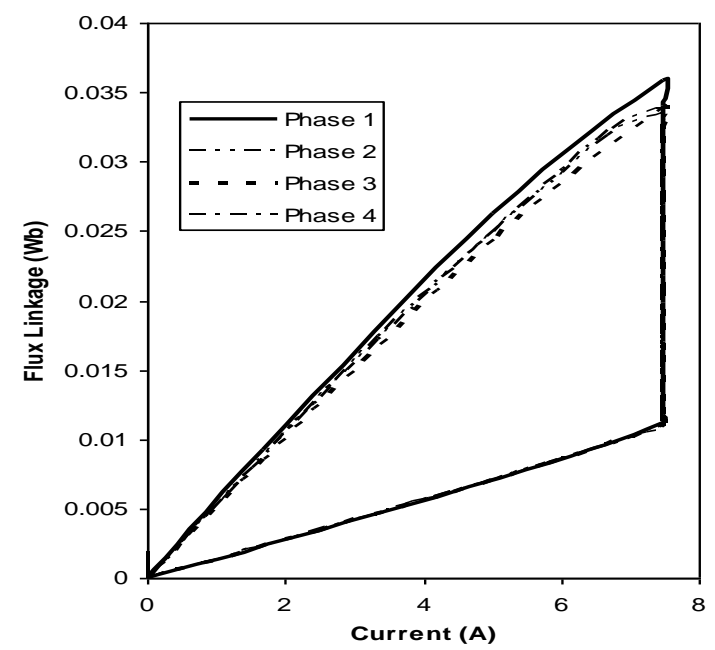

Fig. 3. Flux linkage/current loops when the rotor is $30 \%$ eccentric and the firing angles are $\mathrm{Th} 0=31^{\circ}$ and $\mathrm{ThC}=42^{\circ}$

The machine was modeled using a finite element package (SPEED PC-FEA from The University of Glasgow) and different simulations run for the case of a centered rotor then for an eccentric rotor with $30 \%$ static eccentricity. If the rotor becomes eccentric then the series-connected phases have to be treated individually and energy conversion loops for each phase obtained. Fig. 3 shows the energy loop for the machine when the rotor is eccentric and $\mathrm{Th} 0=31^{\circ}$ and $\mathrm{ThC}=42^{\circ}$. The model is current-controlled (up to $7.5 \mathrm{~A}$ ) and static solutions were obtained with an appropriate current profile to represent the experimental machine operation. The torque in this instance was $0.508 \mathrm{Nm}$ when the rotor was eccentric and 0.498 $\mathrm{Nm}$ when centered, which represents only a $2 \%$ increase; the measured values were 0.47 and $0.51 \mathrm{Nm}$ respectively which is a $6.25 \%$ increase. There are a several probable reasons for the difference in simulated and measured torque, however it should be remembered that the static solutions will not have exactly the same current profile during turn on and off, and the UMP (unbalanced magnetic pull) may be pulling the rotor so that the eccentricity may be higher than initially set (the measured torques were for $33 \%$ nominal static eccentricity whereas the simulation is for $30 \%$ eccentricity). A solution is shown in Fig. 4 where the eccentricity is in the right-hand direction, i.e., the airgap on the left is larger than on the right. It can be seen that there is more flux in the right hand pole than in the left. The dynamic curves will also be nonlinear in terms of the different paths taken when the current is rising and falling [4]. The effect of varying eccentricity is considered in the next section.

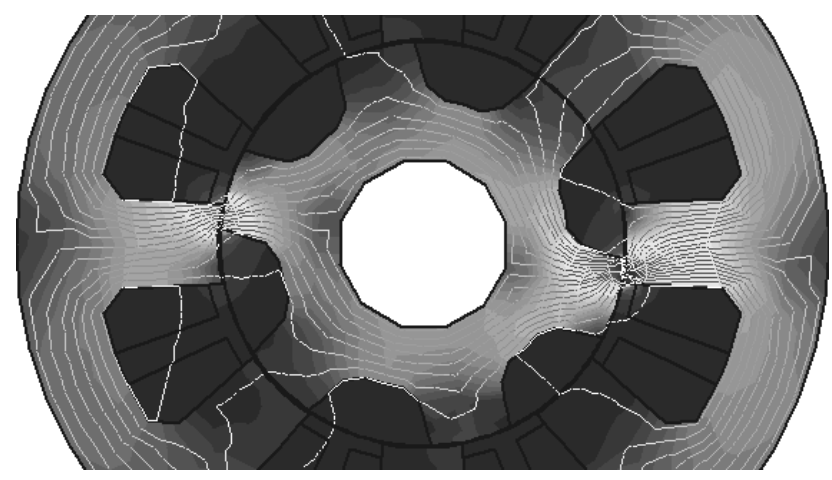

Fig. 4. FEA simulation with phase 1 just about to be switched off

\section{VARIATION OF TORQUE WITH ECCENTRICITY}

The precise degree of eccentricity is difficult to measure since the airgap is only $0.3 \mathrm{~mm}$; and during operation the unbalanced magnetic pull will tend to increase the eccentricity. When the firing angles were $31^{\circ}$ and $42^{\circ}$ and the eccentricity was increased to $45 \%$ then the simulation produced an increase of torque to $0.54 \mathrm{Nm}$ which is an increase in torque of $7.8 \%$. Fig. 5 shows the change in torque with eccentricity while Fig. 6 illustrates the increasing divergence of the current/flux linkage loops at $45 \%$ eccentricity compared to those in Fig. 3 (30\% eccentricity). The percentage changes in torque at $30 \%$ and $45 \%$ eccentricity for the simulation and also the measured change in torque (at $1000 \mathrm{rpm}$ ) are shown in Table 1 . This seems to suggest that the eccentricity may be high due to UMP and that it is approaching $45 \%$.

TABLE I

CHANGE IN TORQUE WITH ECCENTRICITY

\begin{tabular}{cccc}
\hline \hline & $\begin{array}{c}\text { Simulation: } \\
\text { Change in } \\
\text { Torque }(\%)\end{array}$ & $\begin{array}{c}\text { Measured: } \\
\text { Change in } \\
\text { Torque at 1000 } \\
\text { rpm (\%) }\end{array}$ \\
& $30 \%$ & $45 \%$ & $33 \%$ (nominal) \\
Eccentricity & 30.4 & 7.8 & 7.2 \\
Th0 $=31 ;$ ThC $=42$ & 1.8 & 4.4 & 5.5 \\
Th0 $=28 ;$ ThC $=44$ & 2.3 & 5.8 & 5.7 \\
Th0 $=32 ;$ ThC $=48$ & & &
\end{tabular}




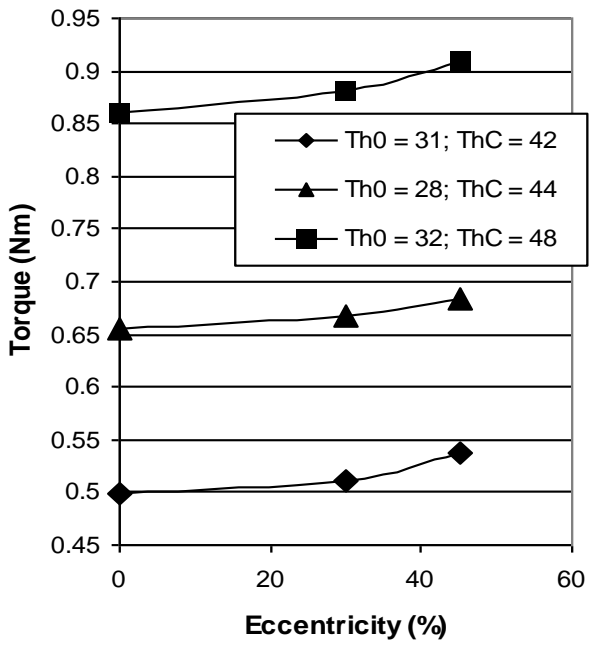

Fig. 5. Change in calculated torque with increasing eccentricity

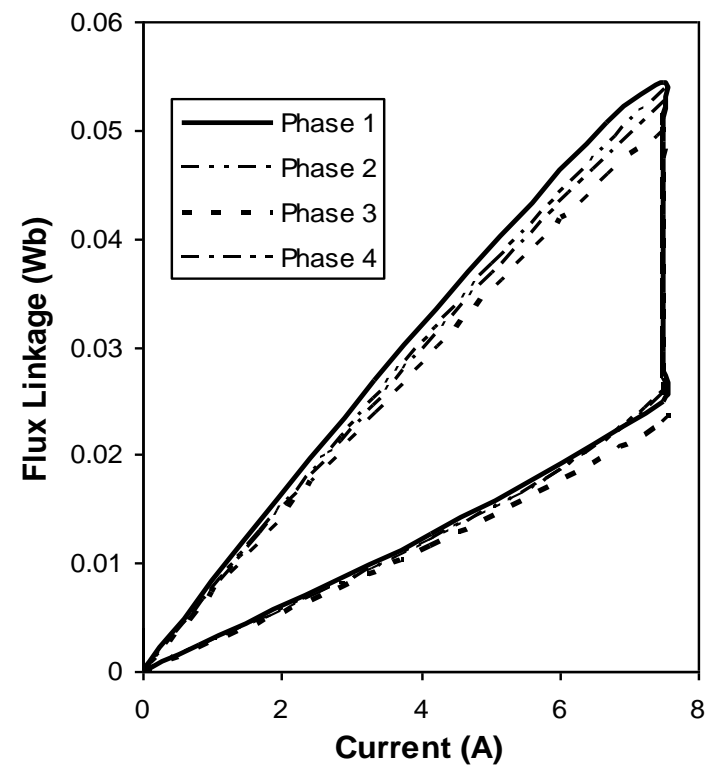

Fig. 6. Flux linkage/current loops when the rotor is $45 \%$ eccentric and the firing angles are $\mathrm{Th} 0=31^{\circ}$ and $\mathrm{ThC}=42$

\section{UnBalanced Magnetic PULL}

The results seem to suggest that the rotor is being further pulled from the center of the stator bore. This can be calculated using a Maxwell stress round the airgap and vectorizing the normal force acting on either the rotor or stator surface. This is shown in Fig. 7 for firing angles $\mathrm{Th} 0=28$; $\mathrm{ThC}=44$. As well as pulsating force there is a net steady force along the $\mathrm{x}$-axis. The rotor is eccentric along the axis and it can be seen that the peak force is when phase 1 (horizontal axis phase) is on (200 N and $350 \mathrm{~N}$ for $30 \%$ and $45 \%$ eccentricities). This force is quit high and possibly enough to move the rotor slightly. The peak torque can be approximated by estimating the peak flux density under each pole of phase 1 when there is maximum current and overlap. At $45 \%$ eccentricity the peak UMP is calculated to be:

$$
\begin{aligned}
& U M P_{\text {peak }}=\frac{B_{\text {pole } 1}^{2}-B_{\text {pole } 2}^{2}}{2 \mu_{0}} \times \text { overlap } \times \text { Lstk } \\
& =\frac{1.7^{2}-0.85^{2}}{8 \times \pi \times 10^{-7}} \times \frac{4.6}{1000} \times 0.075=300 \mathrm{Nm}
\end{aligned}
$$

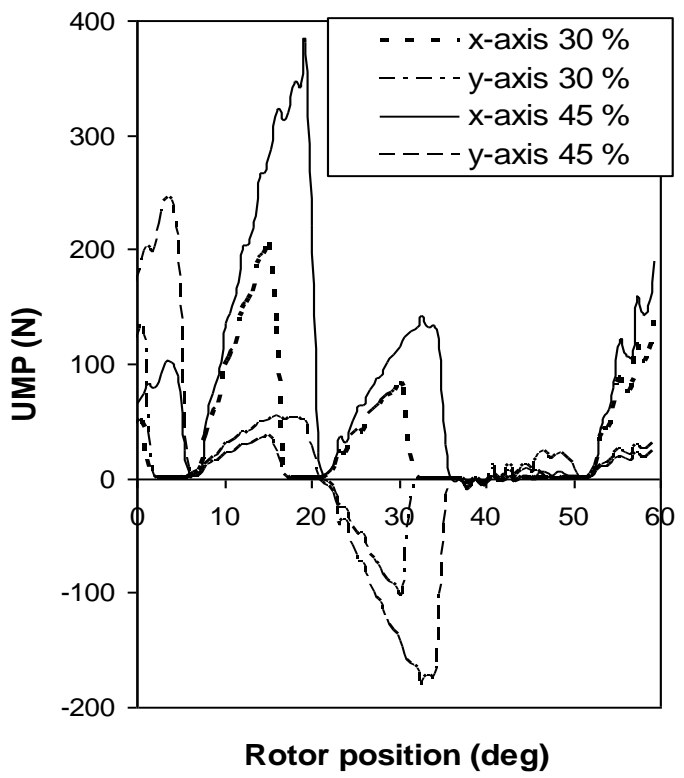

Fig. 7. Unbalanced magnetic pull at $\mathrm{Th} 0=31^{\circ}$ and $\mathrm{ThC}=42$

\section{CONCLUSION}

This paper illustrates that when the rotor in a switched reluctance machine is not centered there can be an increase in torque in the region of a few percent when the machine is operating in full current control mode. This was illustrated using finite element analysis by consideration of the current/flux linkage loops for each phase and verified on an experimental 4-phase machine.

\section{ACKNOWLEDGMENT}

The work was carried out while $\mathrm{Mr}$ Chindurza was a research student with the SPEED Laboratory, University of Glasgow and he acknowledges the financial support from the Laboratory during this period.

\section{REFERENCES}

[1] I. Chindurza, D. G. Dorrell and C. Cossar, "Non-invasive Fault Diagnosis for Switched-Reluctance Machines with Incorrect winding Turns, Inter-turn Winding Faults and Eccentric Rotors", IEEE International Conference on Power Electronics and Drive Systems, Singapore, 17 -19 Nov, 2003, on CD.

[2] N. K. Sheth and K. R. Rajagopal, Effects of Nonuniform Airgap on the Torque Characteristics of a Switched Reluctance Motor, IEEE Trans on Magnetics, Vol 40, No 4, July 2004, pp 2032-2034.

[3] T. J. E. Miller, Switched Reluctance Motors and their Control, Oxford Science Publications, 1993, ISBN 0-19-859387-2.

[4] I. Chindurza, D. G. Dorrell and C. Cossar, "Assessing the Core Losses in Switched Reluctance Machines", IEEE Magnetics Society Intermag Conference, 4-8 April, 2005, Nagoya, Japan. 